\title{
Variation in morphological characters of Marsilea crenata living in floating aquatic, emergent aquatic, and terrestrial habitats
}

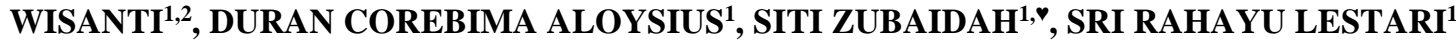 \\ ${ }^{1}$ Department of Biology Education, Faculty of Mathematics and Natural Sciences, Universitas Negeri Malang. Jl. Semarang No. 5 Malang 65145, East \\ Java, Indonesia. Tel./fax.: +62-341-551312, `email: siti.zubaidah.fmipa@um.ac.id \\ ${ }^{2}$ Department Biology, Faculty of Mathematics and Natural Sciences, Universitas Negeri Surabaya Indonesia. Jl. Ketintang, Surabaya 60231, East Java, \\ Indonesia
}

Manuscript received: 1 April 2021. Revision accepted: 23 June 2021

\begin{abstract}
Wisanti, Aloysius DC, Zubaidah S, Lestari SR. 2021. Variation in morphological characters of Marsilea crenata living in floating aquatic, emergent aquatic, and terrestrial habitats. Biodiversitas 22: 2853-2859. Marsilea is a hydrophyte fern that has plasticity often influenced by enviroment. Several of the species with different habitats or geographies show morphological variations. Therefore, this study aims to analyze the variations in morphological characters of $M$. crenata growing in aquatic and terrestrial habitats. A total of 38 plant samples were collected from their natural habitats including floating aquatic, emergent aquatic, and terrestrial types. Morphological variations data included 4 qualitative characters and 9 quantitative characters. The quantitative characters were analyzed by one-way ANOVA to test for differences, while the combination of both characters was analyzed using Principal Component Analysis (PCA) to determine the distribution between groups. The data results showed a separate grouping pattern between aquatic and terrestrial populations. These two groups showed significant differences in 5 quantitative characters and 2 qualitative characters. However, emergent aquatic samples' distribution pattern is closer to the terrestrial group. The characters' similarity of these two populations was in the rhizomes air spaces area, the position between leaflets and absence of red streak on the abaxial lamina. Conclusively, the variations in $M$. crenata's morphological characters indicate that this plant has experienced morphological adaptations to water availability in its environment.
\end{abstract}

Keywords: Emergent aquatic, floating aquatic, Marsilea crenata, morphological variations, terrestrial

\section{INTRODUCTION}

The main characters of Marsilea, which belongs to the Marsileaceae family, include herbaceous creeper with an elongated rhizome and long and upright petiole with four leaflets at the ending part (Schaefer et al. 2011) causing it to resemble a clover (Weakley 2012). This genus is one of the amphibious ferns that develop heterophylly (Lin et al. 2007). Therefore, Marsilea is ubiquitous in amphibious habitats, both aquatic and terrestrial (Johnson 1986), and it varies, depending on the environmental condition. The aquatic species have lengthened rhizome, small petiole, and divided lamina margin. Contrarily, terrestrial species have small yet thick rhizomes and long petiole (Foster and Gifford 1987). Marsilea that grows soaked has semicrenate leaflets, while the non-soaked Marsilea has crenate-to-lobe leaflets (Johnson 1986; Kornas 1988). This morphological variation shows that the terrestrial population is different from the aquatic one, and it is an interesting characteristic of the plant's morphogenesis (Allsopp 1963).

Kornas (1988) had conducted a study on adaptation of morphological variation in five species: $M$. berhautii, $M$. distorta, M. minuta, M.nubica, and M. subterranean, which grew in the basin of Lake Chad, northeast of Nigeria. The result showed the five species adapted to their environmental condition. Lin et al. (2007) on the leaf of one species of $M$. quadrifolia growing in floating aquatic, emergent aquatic, and terrestrial habitats. The result showed difference in stomata and trichome density, leaf and petiole surface mass ratio, spectral characteristics, and photosynthesis performance. Contrarily, $\mathrm{Wu}$ and Kao (2011) studied three Marsilea species namely M. crenata, $M$. quadrifolia, and $M$. schelpiana growing in geographically different areas, which showed significant differences in petiole length, trichome density, leaf dissection index, and total stomata area index. The other species, $M$. minuta, showed a plastically high response to water level (Caton et al. 2010).

Sharma and Bhardwaj (2014) stated Marsilea's morphology is well-known for its plasticity range especially in the vegetative organs due to possession of plastic traits that enhance its adaptation to different environments. Phenotypic plasticity refers to any type of phenotype variation induced by the environment and also affecting an organism's morphology (Sommer 2020). Limited ecological variables play an important role in the adaptation of plant's morphology, physiology, and anatomy to low resource conditions among different populations (Abdusalam and Li 2018). Therefore, plants change their morphological and physiological properties to accommodate adaptability in varied environments (Qi et al. 2020).

Marsilea crenata is the only Marsilea species found in Indonesia, and according to Zhuang (2013), this is a native species in the country. It grows in different types of habitat 
either aquatic or terrestrial, especially in rice fields, open areas with bad light conditions and high temperatures (Setyawati et al. 2015) or on muddy soils with stagnant water, irrigation ditches, and shallow ponds (Afriastini 2003). Marsilea crenata leaves float on the surface when it grows in water, but when on a muddy riverbank, it forms a 'carpet' among grasses and grass-like plants (Calvert and Liessmann 2014).

The study on the variations in morphological character of $M$. crenata with different habitats has been conducted by Agil et al. (2017). Their phenotypic characters were compared in three samples namely $M$. crenata planted on the concrete pots with water and soil media, and the rice field, while the variations were determined by measuring the rhizome, root, petiole, and lamina. The result showed sample one planted on the concrete pot, had longer and more robust roots than the sample grown on rice fields with stagnant water. The conclusion was based on descriptive parameter comparison without being supported by statistical analysis.

Considering that Marsilea species tends to experience phenotypic plasticity according to where it grows, this study aims to analyze the morphological variations of $M$. crenata living in both aquatic and terrestrial habitats. Marsilea's vegetative organs are limited because the sporocarp used for delimitation is not usually found in field populations (Whitten 2012)

The morphological variations among individuals, expressed as intraspecific population diversity, are one of the key components studied in understanding biodiversity. Hence, the data is utilized to characterize the morphological marker of the $M$. crenata populations' morphological marker. According to Ramadiana et al. (2018), morphological marker characterization has long been used as a possible genetic diversity indicator and is easily assessed. Besides, the data generated is used to study phylogeny reconstruction. Although morphological phylogenetic is traditional and sometimes considered outdated, it is still important for rigorous testing and dating of the strict tree of life (Lee and Palcy 2015).

\section{MATERIALS AND METHODS}

\section{Plant materials}

Several $M$. crenata were collected from their natural habitat, at one location in Rejoslamet village, Mojowarno, Jombang district, East Java, Indonesia (coordinates in 7³6'30" South latitude, $112^{\circ} 19^{\prime} 44^{\prime \prime}$ East latitude) with an altitude of $46 \mathrm{M}$ above sea level, where the plants were commonly found growing alongside. Terrestrial $M$. crenata grows outside of the rice fields, while aquatic $M$. crenata grows in ponds. Different habitats-specimens are referred to as a population, including floating aquatic, emergent aquatic, and terrestrial. A total of 38 samples were collected including 15 from floating aquatic, 15 from emergent aquatic, and 8 from terrestrial habitats.

\section{Procedures}

\section{Leaf epidermis preparation}

The leaf specimen was prepared using the clearing technique according to Vasco et al. (2014). Firstly, M. crenata leaves were soaked in sodium hydroxide solution (5\%) for two to three days. After the non-fragile and transparent ones were placed in the watch glass, they were rinsed with aquadest, then bleached with sodium hypochlorite $(5.25 \%)$ for 2 seconds. After turning white, rinsing was performed thrice with aquadest, followed by staining with $1 \%$ safranin.

\section{Rhizome and petiole anatomy preparation}

According to the Johansen protocol, anatomical samples were prepared using the paraffin-embedding technique (Retamales and Scharaschkin 2014). They were dehydrated through the ethanol series, followed by a combination of xylene-ethanol (1:3, 1:2, 1: 1, and 1:0) for 2 hours each, then infiltrated and immersed in paraffin. All of them were cut into transverse sections with $6 \mu \mathrm{m}$ thickness using a rotary microtome (Shibuya manual), then stained using $1 \%$ safranin and mounted using Canada balsam.

\section{Observation and measurement}

Morphological characters referred to in this study were external and internal ones, regarding anatomy. The variation data collected as qualitative characters include rhizome color, lamina margin shape, position between leaflets, and red streaks on the abaxial lamina. Also, quantitative characters collected included lamina length and width ratio, length of internodes, root nodes and petioles (Figure 1), stomata index, rhizomes' air spaces area, and the number of air spaces in rhizomes and petioles. Air space was observed in the aerenchyma tissue located in the of rhizomes' cortex. These are vegetative characters because the presence of sporocarps is rare in M. crenata populations.

Quantitative morphological data were obtained by measuring each fresh specimen's character with three repetitions except for lamina which the length and width were measured on three compound leaves of each specimen. From each of the compound leaves, one leaflet in the lower node and another in the upper node were measured. The qualitative character data observed included rhizome color, lamina margin's shape and red streaks, and the leaflets' position.

An electric microscope (Carl Zeiss Axiostar 10-031) equipped with a digital microscope camera (Dino-lite USB AM 4023X) was used to perform anatomical observations, while images were presented using DinoCapture 2.0 software on a computer screen. Air spaces area on aerenchyma tissue was measured and calculated on digital micrographs with DinoCapture 2.0 software. The stomatal index was obtained by counting the stomata and epidermis cells numbers in one field of view on the abaxial and adaxial surfaces. Observation and measurement were carried out at the lamina's tip, middle, margin, and base with five repetitions for each sample. The stomatal index was calculated using the formula: Stomatal index $=\mathbf{s} / \mathbf{e}+$ 
$\mathbf{s}$ (100) where $\mathbf{s}$ and $\mathbf{e}$ is the number of stomata and epidermis cells per unit leaf area (Maylani et al. 2020).

The qualitative and quantitative character traits obtained from the observations and measurements were scored (Table 1) according to Sneath and Sokal's general recommendations about independence, objectivity, and consistency (Lewens 2011). The score determined by multivariate statistics was used for Principal Component Analysis (PCA).

\section{Data analysis}

Morphometric data on variations in morphological characters were analyzed using statistical methods, and these explained differences and similarities between populations (Remagnino et al. 2017). They were analyzed using univariate and multivariate statistical methods, where the univariate method was carried out with the SPSS statistics 19.0 software program (Gray and Kinnear 2012). Each quantitative variable data for every $M$. crenata sample were tested for their differences using the one-way ANOVA. Multivariate methods were used for qualitative and quantitative characters with ordination and cluster analysis using PCA from the PAST version 3.0 software (Rathinavel 2018). All samples were mapped, and each point of the map represented one or more samples.

\section{RESULTS AND DISCUSSION}

\section{Variation of qualitative characters}

Floating aquatic $M$. crenata is a plant with leaves that float on the water's surface, and other parts of its body are submerged in water. Meanwhile, for the aquatic emergent $M$. crenata, some of its body is submerged in water and the leaves are aerial, approximately $7 \mathrm{~cm}$ above the water surface (Figure 2A, C, and E). Terrestrial populations grow with rhizomes spreading above or below the soil surface to ensure all the leaves, both petioles, and laminae are aerial.

Three $M$. crenata populations showed variations in qualitative characters in the rhizomes' color, the lamina margin's shape, the leaflets' position, and red streaks presence on the abaxial lamina surface. Based on the observations, these four characters' variation is stable in populations of different habitats. The plant's rhizome color in floating and emergent aquatic is green, while the terrestrial is red. Red color also appeared in some terrestrial samples' petiole, besides $M$. crenata populations are distinguished based on the leaflets' position. Leaflets of aquatic floating $M$. crenata were adjoining, while those of aquatic emergent and terrestrial leaflets were tenuous (Figures $2 \mathrm{~B}, \mathrm{D}$, and F).

\section{Variation of quantitative characters}

The three populations in different habitats have significant morphological character variations. The nine quantitative characters' statistical analysis results showed all morphological characters observed in the terrestrial population differed significantly from the aquatic population $(\mathrm{p}=0.05)$ (Table 2$)$. The terrestrial population has shorter nodal root, internodes, and petiole, compared to the aquatic one. The longest nodal root and petioles (11.5 $\mathrm{cm}$ and $15.5 \mathrm{~cm}$ ) were detected in the floating aquatic $M$. crenata compared to those in the emergent aquatic and floating aquatic habitats showed similarity in internodes and petioles length, and stomata index.

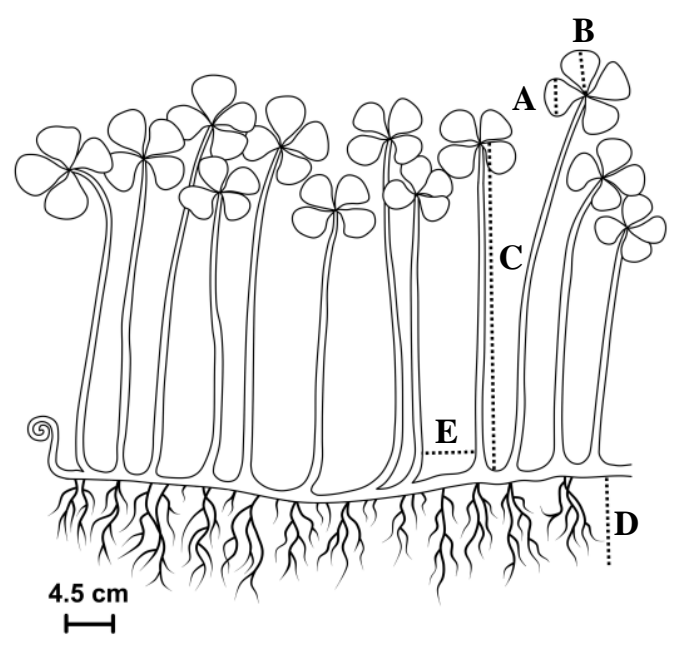

Figure 1. Quantitative characters of Marsilea crenata's rhizome and leaves; A. Lamina width, B. Lamina length, C. Petiole length, D. root nodal length, and E. Internodes length

Table 1. Morphological characters and their states were used in PCA analysis

\begin{tabular}{ll}
\hline Character & Character states (score) \\
\hline Rhizome color & Green $(0)$, Red (1) \\
The lamina margin's shape & Entire (0), Serrate $(1)$ \\
Position between leaflets & Adjoint (0), Tenuous(1) \\
Red streaks on the abaxial lamina & Absent (0), Present $(1)$ \\
Length of the root nodes $(\mathrm{cm})$ & $3-5.5(0), 5.6-7.5(1), 7.6-9.5(2), \geq 9.6(3)$ \\
Length of the rhizome internodes $(\mathrm{cm})$ & $2.5-3.5(0), 3.6-4.5(1), 4.6-5.5(2), 5.6-6.5(3), 6-6-7.5(4)$ \\
Petiole length $(\mathrm{cm})$ & $6.6-8.5(0), 8.6-10.5(1), 10.6-12.5(2), 12.6-14.5(3), \geq 14.6(4)$ \\
Length: width of lamina & $1.06-1.14(0), 1,15-1.23(1), 1.24-1.32(2)$ \\
Number of air spaces on rhizmes & $26-27(0), 28-29(1), 30-31(2)$ \\
Number of air spaces on petioles & $14(0), 15(1)$ \\
Air spaces area on rhizomes $\left(\mathrm{mm}^{2}\right)$ & $0.1(0), 0.2(1)$ \\
Abaxial stomatal index & $13.93-16.93(0), 16.94-19.93(1), 19.94-21.93(2), 21.94-22.93(3)$ \\
Adaxial stomatal index & $13.03-16.02(0), 16.03-19.02(1), 19.03-22.02(2), 22.03-25.2(3)$ \\
\hline
\end{tabular}


The floating leaf's stomatal index showed a hydrophyte character, namely a bigger adaxial surface than the abaxial one, and it was opposite to that of the emergent leaf, while the terrestrial leaf's stomatal index showed the abaxial and adaxial surfaces were almost similar. These three kinds of leaves have significantly different stomatal indices at the abaxial surface. Contrarily, there are no significant differences in the stomatal index at the adaxial surface of floating aquatic and emergent aquatic leaves.

Marsilea crenata anatomy showed hydrophytic characters, namely the presence of aerenchyma, the type wicj has a similar shape with a bicycle wheel, in both of its rhizome and petioles (Manzur et al. 2014). The number of air spaces on the petioles was almost the same as in the three populations (Table 2), but those on the rhizome showed a significant difference $(p=0.05)$, and the terrestrial population fewer air spaces (26) than the aquatic (28-30).

\section{Scatterplot population of $M$. crenata}

The visualization of $38 \mathrm{M}$. crenata samples from three different habitats with PCA was presented with the principal component I (PC I) and principal component II (PC II) axes, as they were divided into two groups with a cumulative contribution value of $82.36 \%$ (69.80\% for PC I and $12.56 \%$ for PC II) (Figure 4). This showed a separate grouping pattern produced based on sampling in different habitats. Group I consisted of the floating and emergent aquatic habitat plants grouped as aquatic $M$. crenata, even though both showed different growth conditions. Aquatic floating $M$. crenata was visibly identified by the entire habit of floating leaves and body submerge in the water, meanwhile, the aquatic emergent was visibly identified by a part of its body that was submerged in the water. Furthermore, group II was dominated by all samples of $M$. crenata terrestrial habitats.

Line projection in the biplot analysis showed the relationship between 13 qualitative and quantitative morphological characters toward the grouping of $38 \mathrm{M}$. crenata samples from three different habitats. The biplot projection display showed the quantitative characters were more dominant than the qualitative toward the plant's grouping. All the characters included in the circle showed aquatic $M$. crenata had varied morphological characters compared to the terrestrial counterpart. The aquatic $M$. crenata sample was correlated by the qualitative characters number 2, 3, and 4 as well as the quantitative characters number $5,6,7,8,9,10$, and 11 . The numbers 2 and 11 were not located in the plots' distribution of neither aquatic nor terrestrial $M$. crenata. The samples shown in the plots' distribution were located in the same direction as the vector line character in the aquatic habitat which indicated an above-average score. In addition, the numbers 3, 4, 5, 6, 7, and 9 have a higher score for aquatic $M$. crenata samples, but aquatic emergent $M$. crenata was located on the vector line character number 8,10 , and 13 . The vector line showed that numbers 2 and 11 were not located in the direction of the sample in both aquatic and terrestrial habitats with a below-average score.
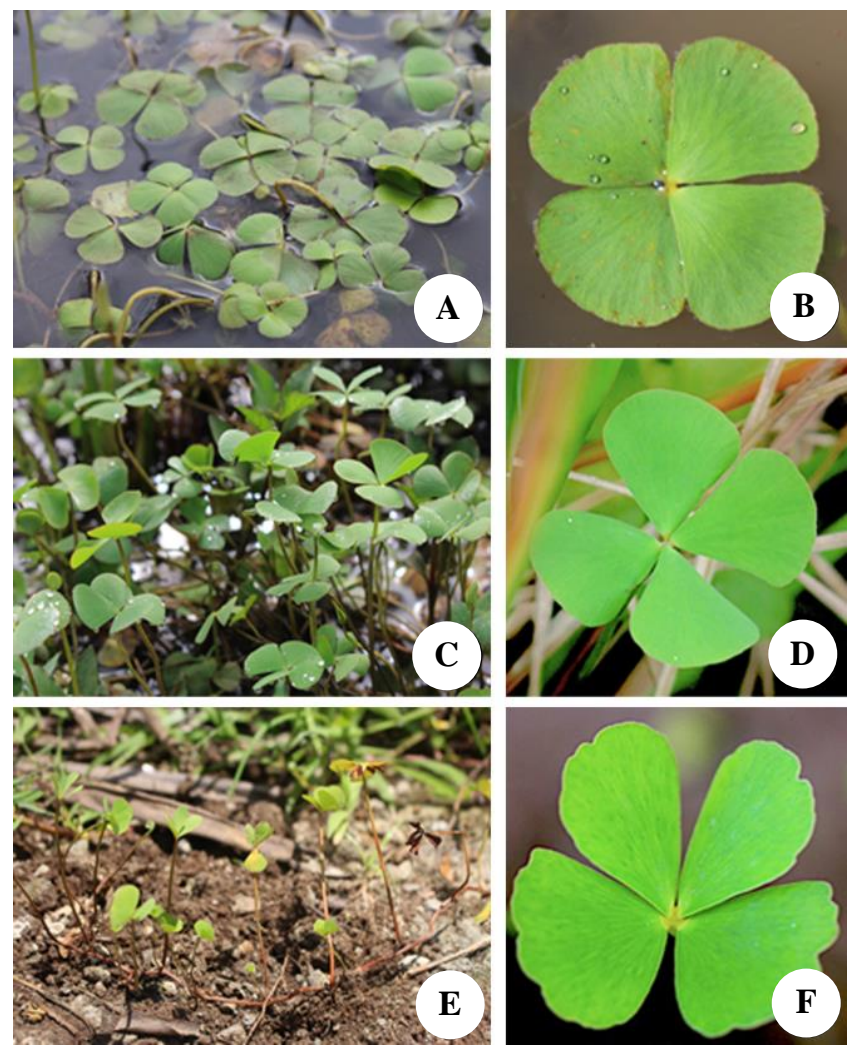

Figure 2. Marsilea crenata's habit and leaf are based on its habitats: aquatic floating (A and B), aquatic emergent (C and D), and terrestrial $(\mathrm{E}$ and $\mathrm{F})$

Table 2. The quantitative character of Marsilea crenata morphology and anatomy with different habitat

\begin{tabular}{llll}
\hline Character & Aquatic emergent & Aquatic floating & Terrestrial \\
\hline Root node length $(\mathrm{cm})$ & $(5.17-8.93) 7.61 \pm 0.25^{\mathrm{b}}$ & $(6.93-11.47) 8.77 \pm 0.36^{\mathrm{c}}$ & $(3-4.75) 3.76 \pm 0.16^{\mathrm{a}}$ \\
Rhizome internodes' length $(\mathrm{cm})$ & $(3.85-6.73) 5.29 \pm 0.28^{\mathrm{b}}$ & $(4.04-7.5) 5.47 \pm 0.27^{\mathrm{b}}$ & $(2.5-5.53) 3.70 \pm 0.36^{\mathrm{a}}$ \\
Petiole length $(\mathrm{cm})$ & $(10.53-13.53) 11.91 \pm 0.23^{\mathrm{b}}$ & $(10.7-15.47) 12.49 \pm 0.40^{\mathrm{b}}$ & $(6.6-9.13) 8.36 \pm 0.73^{\mathrm{a}}$ \\
Length: width of lamina & $(1.05-1.20) 1.11 \pm 0.01^{\mathrm{a}}$ & $(1.06-1.27) 1.12 \pm 0.02^{\mathrm{a}}$ & $(1.06-1.32) 1.19 \pm 0.03^{\mathrm{b}}$ \\
Air spaces number on rhizomes & $(27-29) 28.33 \pm 0.25^{\mathrm{b}}$ & $(30-31) 30.80 \pm 0.10^{\mathrm{c}}$ & $(26-27) 26.25 \pm 0.16^{\mathrm{a}}$ \\
Air spaces number on petioles & $(15) 15.00 \pm 0.00^{\mathrm{b}}$ & $(15) 15.00 \pm 0.00^{\mathrm{b}}$ & $(14-15) 14.50 \pm 0.18^{\mathrm{a}}$ \\
Air spaces area on rhizomes $\left(\mathrm{mm}^{2}\right)$ & $(0.12-0.19) 0.16 \pm 0.01^{\mathrm{a}}$ & $(0.19-0.20) 0.2 \pm 0.01^{\mathrm{b}}$ & $(0.12-0.18) 0.14 \pm 0.01^{\mathrm{a}}$ \\
Abaxial stomata index & $(16.95-22.9) 20.06 \pm 0.42^{\mathrm{c}}$ & $(15.77-19.23) 18.01 \pm 0.36^{\mathrm{b}}$ & $(13.93-18.7) 16.39 \pm 0.58^{\mathrm{a}}$ \\
Adaxial stomata index & $(18.31-25.2) 22.11 \pm 0.52^{\mathrm{b}}$ & $(19.03-24.4) 21.85 \pm 0.42^{\mathrm{b}}$ & $(13.03-18.73) 15.65 \pm 0.71^{\mathrm{a}}$ \\
\hline
\end{tabular}

Note: Morphological characters consisted of the root, rhizomes, petioles, and lamina [(minimum-maximum) mean \pm SE, $\mathrm{n}=15,15$, and 8] . The value on a similar line was followed by different superscripts, representing a significant difference, $\mathrm{p}=0.05$. 

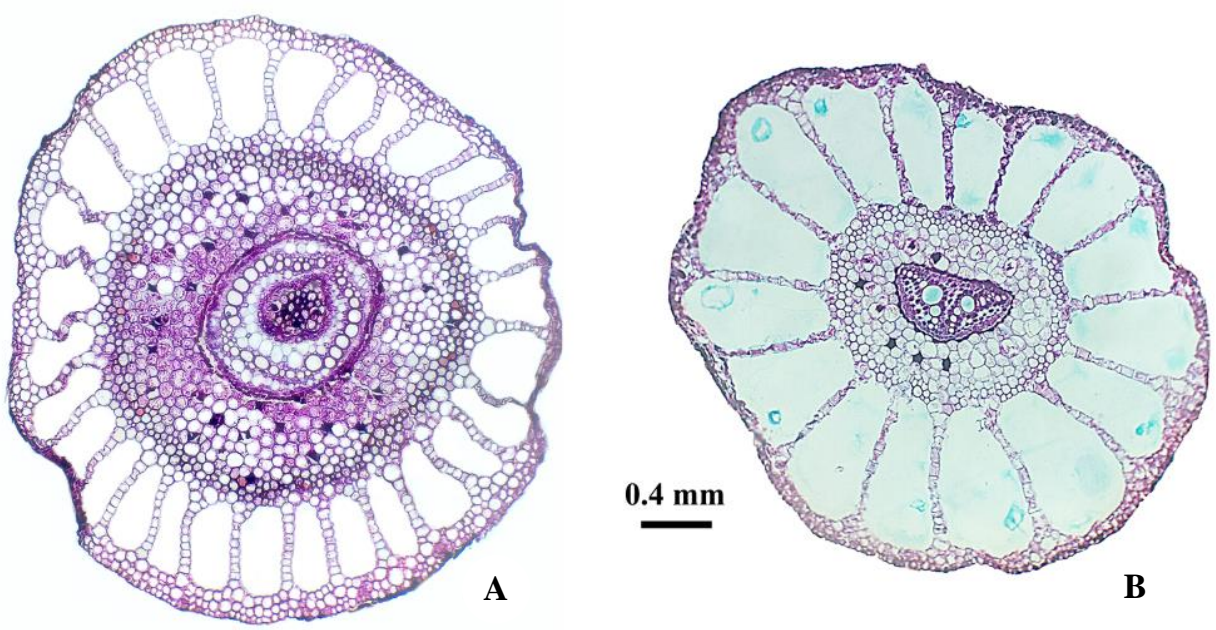

Figure 3. Cross-section of the rhizome (A) and petiole (B) of Marsilea crenata showing the cortex being modified into aerenchyma with quite large air spaces.

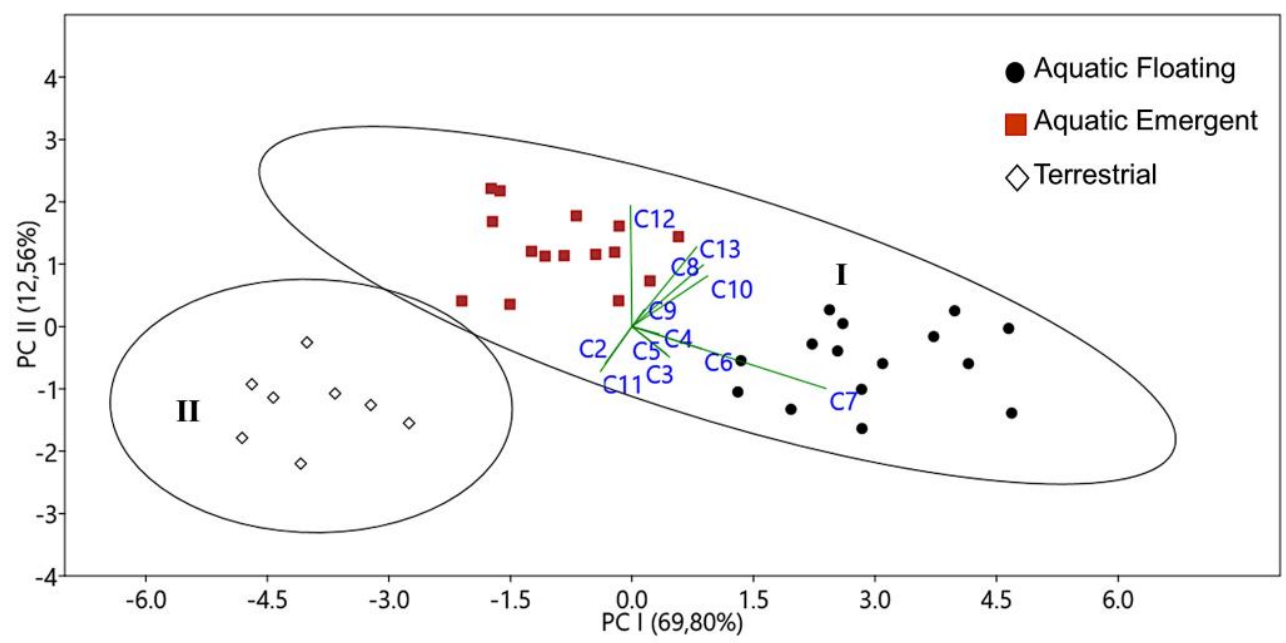

Figure 4. The plot's distribution shows the relationship between 38 samples of $M$. crenata and their 13 morphological characters. Qualitative character: C1: rhizome color; C2: lamina margin's shape; C3: leaflets' position; C4: red streaks' presence on the abaxial lamina. Quantitative character: C5: air spaces area $\left(\mathrm{mm}^{2}\right)$; C6: number of air spaces in the rhizome; C7: length of the rhizome internode $(\mathrm{cm})$; C8: length of the root node $(\mathrm{cm})$; C9: number of air spaces in the petiole; C10: petiole length $(\mathrm{cm})$; C11: ratio of lamina's width to length; C12: stomatal index of adaxial surface; and C13: stomatal index of abaxial surface

Character variations' presence in the aquatic $M$. crenata was presumed to adapt to the aquatic environment. This character is expressed when the plant grows in aquatic conditions. Terrestrial M. crenata did not show any correlation of morphological characters, either qualitative or quantitative. This was proven by the sample plots' distribution where there are no character line vectors as shown in the aquatic habitats. However, it is possible to separate terrestrial $M$. crenata from the aquatic counterpart and the grouping pattern clearly showed that was $M$. crenata grouped according to their habitat type. These data indicated that quantitative characters are more important than qualitative ones and are also used as character identification in the grouping of $M$. crenata from different habitats.
The variation in qualitative and quantitative characters among $M$. crenata populations in different habitats reflects intraspecific variability, which is defined as the differences occurring between various individuals of the same species, recognized through morphological characteristics (Dumont 2018). One of the $M$. crenata's characteristics that varies and shows significant differences between the aquatic and terrestrial samples is the petioles' length. Naturally, aquatic $M$. crenata has longer petioles' length than terrestrial $M$. crenata. Some species rapidly lengthen their stems or petioles by keeping the leaves above the water surface to facilitate gas exchange and light interception (Oliveira et al. 2015). Hence, making it possible to grow leaves that rise to the water surface to carry out photosynthesis in the air providing a diffusion pathway to the roots. This 
character is considered a form of plants' adaption to water depth (Johnson 1986). Conversely, M. quadrifolia planted in the moist soil grow slower than those in the earthen base and is equally smaller (Henderson 1933).

One of the characteristics of wetland plants and dryland plants that have a high tolerance to flooding is aerenchyma, which refers to the tissue with air spaces that provide internal pathways for the oxygen diffusion in organs under stagnance or submergence in water (Cardoso et al. 2013). In many wetland and aquatic plants, aerenchyma develops on shoots and roots (Takahashi et al. 2014), while in $M$. crenata it is commonly found in the rhizome, roots, and leaves. The data analysis results showed that $M$. crenata in aquatic habitats had a wider and more air space on the aerenchyma tissue than the terrestrial counterpart. The study on intraspecific aerenchyma in different habitats showed variations in size. Moreover, rice root aerenchyma develops significantly against soil moisture fluctuations, especially during drought periods and waterlogged conditions (Niones et al. 2012). The aerenchyma of Metasequoia glyptostroboides adventitious roots that grow in the aquatic environments is wider and irregularly arranged than those in the terrestrial (Yang et al. 2019).

Leaf stomata are important plant structures that are very sensitive to environmental changes (Hong et al. 2018; Zhu et al. 2018). The density and size are relatively stable characteristics hence these characters are often used to understand plant species adaptation or response to the changing environmental conditions (Wang et al. 2014). Drought stress or water status promotes changes in leaf morpho-anatomical traits including stomata density and leaf thickness (Anjum et al. 2011; Wang et al. 2013). The results showed that the stomatal index of aquatic $M$. crenata was bigger than terrestrial $M$. crenata, proving that different populations of the same species have different stomata adaptability to different environments. Marsilea crenata which was supposed to live in aquatic habitats, responded with decreased stomatal density when it grows in a place without water. This is contrary to the study by Zhao et al. (2015) which showed a significant decrease in groundwater content stimulated stomata formation in maize to ensure a significant increase in stomatal density.

There are remarkable differences between M. crenata's qualitative characters between those grown in aquatic and terrestrial environments. Floating leaves tend to have a thin shape with an entire margin, but terrestrial leaves are thicker with a serrate margin. This species thrives even in an environment that has no puddle, and a such plant is thought to experience a morphological variation that allows adaptation to environmental change ( $\mathrm{Li}$ et al. 2019). A species ability to respond and adapt to environmental change is crucial (Kristensen et al. 2018). Ecological variables limitation plays an important role in developing and adapting morphological, physiological, and anatomical characters of plants under low resource conditions among different populations (Nascimbene and Marini 2015; Abdusalam and Li 2018).

Similar to the previous explanation, morphological variation occurred in $M$. crenata growing naturally on its habitat or cultivated, which showed that this plant adapts to water availability. Without this variation, the population of $M$. crenata tends to not survive under environmental changing factors. According to several investigations, Marsilea's plasticity nature is indicated by the variation in its vegetative characters (Whitten et al. 2012; Sharma and Bhardwaj 2014). The vegetative character of Marsilea has a range of plasticity (Sharma and Bhardwaj 2014), which depends on the habitat's water depth and this is also detected in M. minuta (Caton et al. 2010). In other words, when environmental factors strongly influence phenotypic traits' variations, it represents both plastic and adaptive mechanisms (Kaliontzopoulou et al. 2018).

Variation analysis on $M$. crenata's morphological character by quantitative approach provided essential knowledge about plant adaptation to habitat conditions. On a local scale, water availability is an important control for the plant's morphological variations. The evidence of qualitative and quantitative adaptive help explain $M$. crenata's ability to grow well in aquatic and terrestrial habitats. However, the morphological variation as presented in the results was not concluded yet as a form of plasticity since the sample used was naturally obtained but at least the data tended to plasticity.

\section{ACKNOWLEDGEMENTS}

The authors are grateful to the following students: Fajrul Falah, Eka Setiawan, Gilang Noval Abdillah and Bil Billa devoted their energies to work during $M$. crenata specimens' exploration and collection; Hanif Fauzan that helped to create the graphic designs. The authors are also grateful to the head of the Plant Development Structure Laboratory, Faculty of Biology, Gadjah Mada University, Yogyakarta, Indonesia, which helped prepare the rhizome and petiole anatomy.

\section{REFERENCES}

Abdusalam A, Li Q. 2018. Morphological plasticity and adaptation level of distylous Primula nivalis in a heterogeneous alpine environment. Plant Divers 40 (6): 284-291. DOI: 10.1016/j.pld.2018.11.003.

Afriastini JJ. 2003. Marsilea crenata C. Presl. In: De Winter WP and Amoroso VB (eds.) Plant Resources of Southeast Asia. Cryptogams: Ferns and Fern Allies. Prosea Foundation, Bogor, Indonesia.

Agil M, Kusumawati I, Purwitasari N. 2017. Phenotypic variation profile of Marsilea crenata Presl. cultivated in water and in the soil. J Bot 2017: 1-6. DOI: 10.1155/2017/7232171.

Allsopp A. 1963. Morphogenesis in Marsilea. J Linn Soc Bot 58 (373): 417-427. DOI: 10.1111/j.1095-8339.1990.tb00911.x.

Anjum SA, Xie XY, Wang LC, Saleem MF, Man C, Lei W. 2011. Morphological, physiological and biochemical responses of plants to drought stress. Afr J Agric Res 6 (9): 2026-2032. DOI: 10.5897/AJAR10.027.

Calvert G, Liessmann L. 2014. Wetland Plants of the TownsvilleBurdekin Flood Plain. Lower Burdekin Landcare Association Inc., Ayr.

Cardoso JA, Rincón J, Jiménez JC, Noguera D, Rao IM. 2013. Morphoanatomical adaptations to waterlogging by germplasm accessions in a tropical forage grass. AoB PLANTS 5: 1-14. DOI: 10.1093/aobpla/plt047.

Caton BP, Mortimer M, Hill JE, Johnson DE. 2010. A Practical Field Guide to Weeds of Rice in Asia. IRRI Books Second Edition. 
International Rice Research Institute, Los Baños, Philippines. DOI: 10.22004/ag.econ.164472.

Dumont ER. 2018. Intraspecific Variation in The Sensitivity of Aquatic Macrophytes to Chemical Contamination: The Case of Copper [Thesis]. Université Toulouse III Paul Sabatier (UT3 Paul Sabatier), Toulouse. [French]

Foster SA, Gifford EM. 1987. Morphology and Evolution of Vascular Plants. W.H. Freeman and Company, New York.

Gray CD, Kinnear PR. 2012. IBM SPSS Statistics 19 Made Simple. Psychology Press, Canada

Henderson RV. 1933. The development and structure of the juvenile leaves in Marsilea quadrifolia with notes on the anatomy of the stem and adult petiole. Proc Ind Acad Sci 42: 61-72.

Hong T, Lin H, He D. 2018. Characteristics and correlations of leaf stomata in different Aleurites montana provenances. PloS ONE 13 (12): 1-10. DOI: 10.1371/journal.pone.0208899 D.

Johnson DM. 1986. Systematics of the New World species of Marsilea (Marsileaceae). Sys Bot Monogr 11: 1-87. DOI: 10.2307/25027626.

Kaliontzopoulou A, Pinho C, Martínez-Freiría F. 2018. Where does diversity come from? Linking geographical patterns of morphological, genetic, and environmental variation in wall lizards. BMC Evol Biol 18 (1): 1-13. DOI: 10.1186/s12862-018-1237-7.

Kornas J. 1988. Adaptive strategies of Marsilea (Marsileaceae: Pteridophyta) in the Lake Chad Basin of N.E. Nigeria. Fern Gaz 13: 231-243.

Kristensen TN, Ketola T, Kronholm I. 2018. Adaptation to environmental stress at different timescales. Ann N.Y. Acad Sci 1476 (1): 1-18 DOI: $10.1111 /$ nyas. 13974

Lee MSY, Palci A. 2015. Morphological phylogenetics in the genomic age. Curr Biol 25 (19): 922-929. DOI: 10.106/j.cub.2015.07.009.

Lewens T. 2011. Pheneticism reconsidered. Biol Philos 27 (2): 159-177. DOI: $10.1007 / \mathrm{s} 10539-011-9302-2$.

Li G, Hu S, Hou H, Kimura S. 2019. Heterophylly: phenotypic plasticity of leaf shape in aquatic and amphibious plants. Plants 8 (10): 1-13. DOI: $10.3390 /$ plants8100420

Lin C-H, Lin B-L, Kao W-Y. 2007. Leaf characteristic and photosynthetic performance of floating, emergent and terrestrial leaves Marsilea

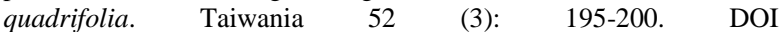
10.6165/tai.2007.52(3).195.

Manzur ME, Grimoldi AA, Insausti P, Striker GG. 2014. Radial oxygen loss and physical barriers in relation to root tissue age in species with different types of aerenchyma. Funct Plant Biol 42 (1): 9-17. DOI: 10.1071/FP14078

Maylani ED, Yuniati R, Wardhana W. 2020. The Effect of leaf surface character on the ability of water hyacinth, Eichhornia crassipes (Mart.) Solms. to transpire water. Proceeding of IOP Conference Series: Materials Science and Engineering 902. 4th International Symposium on Current Progress in Functional Materials, Bali, 6-7 November 2019. DOI: 10.1088/1757-899X/902/1/012070. [Indonesian]

Nascimbene J, Marini L. 2015. Epiphytic lichen diversity along elevational gradients: biological traits reveal a complex response to $\begin{array}{lllll}\text { water and energy. J Biogeogr } 42 & \text { (7): 1222-1232. }\end{array}$ DOI:10.1111/jbi.12493.

Niones JM, Suralta RR, Inukai Y, Yamauchi A. 2012. Field evaluation on functional roles of root plastic responses on dry matter production and grain yield of rice under cycles of transient soil moisture stresses using chromosome segment substitution lines. Plant Soil 359 (1) 107-120. DOI: 10.1007/s11104-012-1178-7.

Oliveira AS de, Ferreira CS, Graciano-Ribeiro D, Franco AC. 2015 Anatomical and morphological modifications in response to flooding by six Cerrado tree species. Acta Bot Bras 29 (4): 478-488. DOI: 10.1590/0102-33062014abb0035.

Qi J, Liu W, Jiao T, Hamblin A. 2020. Variation in morphological and physiological characteristics of wild Elymus nutans ecotypes from different altitudes in the northeastern Tibetan plateau. J Sens 2020: 1 11. DOI: $10.1155 / 2020 / 2869030$.
Ramadiana S, Hapsoro D, Yusnita. 2018. Morphological variation among fifteen superior robusta coffee clones in Lampung Province, $\begin{array}{llll}\text { Indonesia. Biodiversitas } 19 & \text { (4): 1475-1481. DOI: }\end{array}$ 10.13057/biodiv/d190438.

Rathinavel K. 2018. Principal component analysis with quantitative traits in extant cotton varieties (Gossypium hirsutum L.) and parental lines for diversity. Curr Agric Res 6 (1): 54-64. DOI: 10.12944/CARJ.6.1.07.

Remagnino P, Mayo S, Wilkin P, Cope J, Kirkup D. 2017. Computational Botany: Methods for Automated Species Identification. SpringerVerlag $\mathrm{GmbH}$, Berlin.

Retamales HA, Scharaschkin T. 2014. A staining protocol for identifying secondary compounds in Myrtaceae. Appl Plant Sci 2 (10): 1-8. DOI: 10.3732/apps.1400063.

Schaefer H, Carine MA, Rumsey FJ. 2011. From European priority species to invasive weed: Marsilea azorica (Marsileaceae) is a Misidentified alien. Sys Bot 36 (4): 845-853. DOI: $10.1600 / 036364411$ X604868.

Setyawati T, Narulita S, Bahri IP, Raharjo GT. 2015. A Guide Book to Invasive Plant Species in Indonesia. Research, Development and Innovation Agency Ministry of Environment and Forestry Republic of Indonesia, Bogor, Indonesia. [Indonesian]

Sharma P, Bhardwaj N. 2014. Assessment of genetic diversity among Marsilea populations of Hadauti plateau as revealed by RAPD markers. IJPAB 2 (2): 254-261.

Sommer RJ. 2020. Phenotypic plasticity: from theory and genetics to current and future challenges. Genetics 215 (1): 1-13. DOI: 10.1534/genetics. 120.303163

Takahashi H, Yamauchi T, Colmer TD, Nakazono M. 2014. Aerenchyma formation in plants. In: van Dongen JT, Licausi F (eds) Low-Oxygen Stress in Plants, Plant Cell Monographs. DOI: 10.1007/978-3-70911254-0_13.

Vasco A, Thadeo M, Conover M, Daly DC. 2014. Preparation of samples for leaf architecture studies, a method for mounting cleared leaves. Appl Plant Sci 2 (9): 1-4. DOI: 10.3732/apps.1400038.

Wang JH, Li SC, Sun M, Huang W, Cao H, Xu F, Zhou NN, Zhang SB. 2013. Differences in the stimulation of cyclic electron flow in two tropical ferns under water stress are related to leaf anatomy. Physiol Plant 147 (3): 283-295. DOI: 10.1111/j.1399-3054.2012.01657.x

Wang R, Yu G, He N, Wang Q, Xia F, Zhao N, Xu Z, Ge J. 2014. Elevation-related variation in leaf stomatal traits as a function of plant functional type: evidence from Changbai Mountain, China. PLoS ONE 9 (12): e115395. DOI: 10.1371/ journal.pone.0115395.

Weakley AS. 2012. Flora of the Southern and Mid-Atlantic States. UNC Herbarium, North Carolina Botanical Garden, United States of America.

Whitten WM, Jacono CC, Nagalingum NS. 2012. An expanded plastid phylogeny of Marsilea with emphasis on North American species. Am Fern J 102 (2): 114-135. DOI: 10.1640/0002-8444-102.2.114.

Wu TC, Kao WY. 2011. Ecophysiological traits of leaves of three Marsileaspecies distributed in different geographical regions. Taiwania 56 (4): 279-286. DOI: 10.6165/tai.2011.56(4).279.

Yang C, Zhang X, Wang T, Hu S, Zhou C, Zhang J, Wang Q. 2019. Phenotypic plasticity in the structure of fine adventitious Metasequoia glyptostroboides roots allows adaptation to aquatic and terrestrial environments. Plants 8 (501): 1-12. DOI: 10.3390/plants8110501.

Zhao W, Sun Y, Kjelgren R, Liu X. 2015. Response of stomatal density and bound gas exchange in leaves of maize to soil water deficit. Acta Physiol Plant 37 (1): 1-9. DOI: 10.1007/s11738-014-1704-8.

Zhu J, Yu Q , Xu C, Li J, Qin G. 2018. Rapid estimation of stomatal density and stomatal area of plant leaves based on object-oriented classification and its ecological trade-off strategy analysis. Forests 9 (616): 1-18. DOI: 10.3390/f9100616.

Zhuang X. 2013. Marsilea crenata. The IUCN Red List of threatened species. DOI: 102305/IUCN.UK.2011-1.RLTS/T16820A6523971. 